6-14-2016

\title{
Learning to Mediate: Teacher Appropriation of Dynamic Assessment
}

\author{
Kristin Davin \\ Loyola University Chicago, kdavin@luc.edu \\ Jose David Herazo \\ Universidad de Cordoba, Colombia, jherazo4@gmail.com \\ Anamaria Sagre \\ Universidad de Cordoba, Colombia, asagreba@gmail.com
}

Follow this and additional works at: https://ecommons.luc.edu/education_facpubs

Part of the Education Commons

\section{Author Manuscript}

This is a pre-publication author manuscript of the final, published article.

\section{Recommended Citation}

Davin, Kristin; Herazo, Jose David; and Sagre, Anamaria. Learning to Mediate: Teacher Appropriation of Dynamic Assessment. Language Teaching Research, , : 1-20, 2016. Retrieved from Loyola eCommons, Education: School of Education Faculty Publications and Other Works, http://dx.doi.org/10.1177/ 1362168816654309

This Article is brought to you for free and open access by the Faculty Publications and Other Works by Department at Loyola eCommons. It has been accepted for inclusion in Education: School of Education Faculty Publications and Other Works by an authorized administrator of Loyola eCommons. For more information, please contact ecommons@luc.edu.

\section{(c) $($ () $\ominus$}

This work is licensed under a Creative Commons Attribution-Noncommercial-No Derivative Works 3.0 License. (c) Kristin J. Davin, José D. Herazo, and Anamaría Sagre, 2016 
Language Teaching Research

DOI: $10.1177 / 1362168816654309$

Learning to Mediate: Teacher Appropriation of Dynamic Assessment

Kristin J. Davin, Loyola University Chicago

Jose David Herazo and Anamaria Sagre, Universidad de Cordoba, Colombia

\section{Introduction}

Although approaches to dynamic assessment (DA) vary substantially across disciplines such as math (see Desoete, Roeyers, Buysse, \& De Clerq, 2002), teacher education (see Golombek, 2011), and educational psychology (Lidz, 2014), most second language (L2) classroom approaches share two defining characteristics: (1) teachers mediate students' learning through the use of graduated and contingent prompting, and (2) teachers track learners' responses to prompting to design future instruction. Mediation involves the intentional introduction of signs, often by the teacher, to reorganize ongoing activity (Wertsch, 2007). Learners' errors in the L2 classroom offer one window into their instructional needs and provide the teacher with an opportunity to mediate. In much of the existing L2 DA research, the teacher uses prompts for mediation (Antón, 2009; Davin, 2013; Poehner, 2008), defined as signs that are directed toward the learner to draw attention to an error and encourage reformulation. Prompts are graduated so that each subsequent prompt provides more explicit information about how to reformulate a response, giving the learner increasingly explicit forms of regulation and providing multiple opportunities for reformulation (Aljaafreh \& Lantolf, 1994). Each subsequent prompt is contingent upon learners' response and must be "sufficiently explicit to be of value to learners but not so explicit that it limits learners from fully contributing to the activity" (Lantolf \& Poehner, 2014, p. 159). Graduated and contingent prompts engage learners in trying to figure out the reason for their errors, promoting increased control of 
Language Teaching Research

DOI: $10.1177 / 1362168816654309$

the language (Rassaei, 2014) and increasing learners' sense of agency (Lantolf, 2012).

The teacher evaluates how the learner responds to prompting to design subsequent instruction (Ableeva, 2008; Antón, 2009; Lantolf \& Poehner, 2013; Poehner \& van Compernolle, 2013). A decrease in the quality and frequency of prompts required by a learner over time is taken as indication that the learner is developing and moving from a reliance on other-regulation to self-regulation; that is, achieving a greater degree of independence and self-reliance (Aljaafreh \& Lantolf, 1994). For example, a learner who requires substantial explicit prompting to reformulate an utterance likely requires more subsequent instruction than a learner who required little implicit prompting. Tracking learners' needs in this way permits the teacher to make data based decisions in the classroom, related to which learners may require small group instruction, individualized instruction, or no additional instruction at all.

Perhaps due to its contingent and graduated nature (Aljaafreh and Lantolf, 1994), mediating student learning during whole class interacion is challenging. A teacher must make inferences about learners' current level of understanding and provide forms of mediation that are likely to result in increased awareness and control of the language. This complexity is magnified in the classroom setting in which a teacher must engage a group of diverse learners whose level of awareness and language control varies and thus may require differing forms of mediation during a fixed amount of instructional time. In addition, teachers must continually assess individuals' responses to mediation. Although several studies have explored how teachers' mediate and track students' learning while implementing DA in intact classrooms (Author, xxxx; Lantolf \& Poehner, 2011a), research to date has not examined how teachers learn to carry out these two distinctive 
Language Teaching Research

DOI: $10.1177 / 1362168816654309$

features of DA. For many teachers, sociocultural pedagogies that emphasize dialogic mediation to promote learners' increasing self-regulation are unfamiliar and challenging (van Compernolle \& Henery, 2015; Williams, Abraham, \& Negueruela-Azarola, 2013). These pedagogies may not align with teachers' existing conceptualizations of what it means to teach, especially when those conceptualizations are based on teachers' own observations and experiences rather than on formal instruction. Data in the present study are drawn from a larger investigation in which we provided four teachers with formal instruction on DA and mediated their implementation across three lessons. This article describes each teacher's changing practice as related to two of the defining characteristics of DA. Two research questions guided this investigation:

(1) How does teachers' ability to provide graduated and contingent mediation change as they implement DA?

(2) How does teachers' ability to track learners' responses to mediation change as they implement DA?

\section{Dynamic Assessment}

Vygotsky criticized assessments that measured what a learner was able to accomplish independently, contending that it was more important to describe the underlying sources of one's development and bring out future development (Vygotsky, 1987). From this theoretical foundation, DA emerged as a way to diagnose learners' maturing psychological functions (i.e., their zone of proximal development), such as voluntary attention, problem-solving capacity, and logical thinking, so that a mediator could intervene, providing mediation to push the learner to the next developmental stage (Chaiklin, 2003; Song \& Kellogg, 2011). Thus, Vygotsky saw cognition as modifiable in 
Language Teaching Research

DOI: $10.1177 / 1362168816654309$

that higher mental functions developed as a result of participation in socially mediated activity. In this way, learning was a source of development but not all learning resulted in development. Vygotsky wrote, "developmental processes do not coincide with learning processes. Rather, the developmental process lags behind the learning process; this sequence results in the zone of proximal development" (Vygotsky, 1978, p. 90).

Although DA originated in educational psychology and intelligence testing, scholars of L2 teaching and learning appropriated DA to promote and assess language development, adopting a more assistance-oriented (Chaiklin, 2003) definition of the ZPD. L2 DA has the potential to promote cognitive reorganization that may result in the development of higher mental functioning because it provides alternative forms of meaning-based mediation. The primary goal of the mediator, usually a teacher rather than a psychologist, is to promote and assess learners' ability to communicate in the L2. Because learners' errors may be indicative of such ability, the teacher responds to erroneous utterances by providing mediation that guides the learner to become aware of the nature of their errors to correctly reformulate what they want to say. Mediation is intended to transcend the task at hand and promote learners' awareness and control of the linguistic forms they produce, a form of self-regulation. Simultaneously, the teacher endeavors to evaluate how the learner responds to the mediation offered so that future instruction can be better tailored to the learner's emerging communicative abilities.

Two distinct approaches to L2 DA exist, termed interactionist and interventionist approaches (Lantolf \& Poehner, 2014). In interactionist L2 DA approaches, the mediator emphasizes learner development, using un-scripted forms of mediation, expertly calibrated to a learner's emerging needs and to promote control of the language system 
Language Teaching Research

DOI: $10.1177 / 1362168816654309$

during attempts to communicate. Much of the existing research on L2 DA conducted in dyads with one teacher and one learner utilizes an interactionist approach (Ableeva, 2008; Antón, 2009; Poehner \& van Compernolle, 2013; Poehner, 2008). In interventionist L2 approaches, the teacher emphasizes assessment, providing pre-scripted prompts as mediation to assess learners' emerging linguistic capabilities based on the frequency and quality of prompts needed for correct reformulation. Many classroom DA investigations (Author, Colleague, \& Colleague, xxxx; Author, xxxx; Lantolf \& Poehner, 2011a), as well as computerized DA approaches (Poehner \& Lantolf, 2013; Poehner, Zhang, \& Lu, 2015), utilize an interventionist approach.

\section{Methods}

$1 \quad$ Context and participants

Convenience sampling was used to select a varied pool of participants, including two pre-service teachers training to be foreign language teachers in the United States (USA) and two in-service teachers teaching English-as-a-Foreign-Language in Colombia. All teachers selected one of their classes in which to implement DA. These classes, all in public schools, generally had approximately 20 to 45 students. Table 1 displays the information about each teacher.

[Insert Table 1 about here]

While the two teachers selected from Colombia each had 10 years of experience teaching English, those selected from the USA were pre-service teachers engaged in student 
Language Teaching Research

DOI: $10.1177 / 1362168816654309$

teaching as part of their teacher preparation program and each had less than a year of teaching experience. Before the study began, each of the teachers had read about sociocultural theory in their teacher preparation programs, but none were familiar with DA.

\section{$2 \quad$ DA training}

The researchers designed a series of professional development workshops through which to prepare the four teachers to implement DA. The first author conducted the program with the pre-service teachers in the USA and the second two authors conducted the program with the in-service teachers in Colombia. Before the first workshop, teachers were provided with a copy of the second edition text Dynamic Assessment in the Foreign Language Classroom: A Teacher's Guide published by Lantolf and Poehner (2011b) and asked to read a portion that gave an overview of DA (pp. 40-66). Next, during the workshop, participants discussed the differences between formative and summative assessment, the characteristics of DA and its origins in sociocultural theory, explored different approaches to DA, and discussed the affordances and constraints of each for different classroom contexts. Over the following week, the teachers read examples of DA implementation in L2 classrooms (pp. 67-90). During the second DA workshop, teachers discussed each example of DA presented in the text. They then engaged in a think-writepair-share activity focused on how they might implement DA in their own classrooms. During the sharing phase, the researcher and teachers offered suggestions to strengthen each participant's ideas. Following the two DA workshops, teachers wrote a proposal describing how they intended to implement DA in their own classrooms. The researchers 
Language Teaching Research

DOI: $10.1177 / 1362168816654309$

gave the teachers freedom to either create their own approach to DA or use an approach described in the text. The researchers provided feedback on these proposals.

Participants were asked to implement DA over a series of three lessons, each of which was recorded. They reflected on each instance of DA implementation and received additional feedback from the instructors. While some teachers chose to use the same DA approach for all three lesson recordings, others decided to tweak their approach in subsequent lessons. Table 2 shows the DA approach used by each teacher in each lesson recording.

[Insert Table 2 about here]

\section{$3 \quad$ Data collection}

Data sources included lesson video recordings, written artifacts, and participants' oral reflections collected through stimulated recall. Four lessons were recorded for each participant, resulting in a data set of 16 lessons. Due to IRB constrains, data collection procedures varied in the two settings. In Colombia, the researchers recorded and transcribed each of the four lessons. In the USA, researchers did not have permission to enter participants' classrooms. Thus, the pre-service teachers recorded their own lessons and transcribed a 10-minute portion in which they implemented DA. As a result, data in the present study reflect smaller samples for the pre-service teachers.

The first lesson recording took place before the professional development series began, for which participants were asked to select one lesson in which they planned to dialogically interact with learners. These were labeled Pre-DA lessons. After the first 
Language Teaching Research

DOI: $10.1177 / 1362168816654309$

lesson recording and the professional development series, the researchers asked

participants to write a DA proposal that outlined their DA implementation plan. These

proposals were collected and analyzed. Three additional lesson recordings took place

after the DA workshops, based on participants' own selection of lessons. The time between each recording varied based on the schedule of the participants, but was approximately two to four weeks. We labeled these lessons $D A 1, D A 2$, and $D A 3$.

Data sources also included written artifacts and oral reflections. Due to contextual differences, the researchers collected written reflections (in English) from the two U.S. teachers and conducted stimulated recall sessions with the two Colombian teachers (in Spanish) after each lesson recording. During these reflections, participants were asked to explain their approach to responding to learners' errors in the case of the pre-DA lesson and, in the case of the latter three lessons, their approach to DA implementation. Lesson artifacts were also collected, including lesson plans and any records used by the teacher to track student progress.

\section{$4 \quad$ Data analysis}

We transcribed and engaged in three rounds of coding for all lesson recordings from the data set. We limited data analysis in the present study to mediation sequences, defined as insertion sequences in which the teacher interrupted on-going activity to address a learner's error (van Compernolle, 2013). During the initial round of coding, we coded all mediation sequences $(\mathrm{N}=115)$. Each mediation sequence consisted of a student error, usually preceded by teacher elicitation, and followed by all subsequent turns in which the teacher or student addressed the error. We excerpted the mediation sequences from the transcripts for the second round of coding in which we coded each turn by the 
Language Teaching Research

DOI: $10.1177 / 1362168816654309$

teacher and learners. Teacher turns were coded as recasts ${ }^{1}$ or prompts. Recasts were defined as "teacher's reformulation of all or part of a student's utterance, minus the error" (Lyster \& Ranta, 1997, p. 46). Prompts referred to discursive moves by the teacher that encouraged learners to reformulate their own error. Learner turns were coded either as error or no error. We also counted the number of teacher turns in each mediation sequence to compare averages for each lesson. During the third round of coding, we analyzed all mediation sequences to determine the extent to which prompts were graduated (Nassaji, 2009). Using our data set, we determined that teachers' prompts fell into four categories based on the information that they provided to learners. Prompts served to indicate: (1) the existence of an error, (2) the location of the error, (3) the nature of the error (i.e. syntax, aspect), and (4) how to correct the error. Using these four categories along with the category of recasts, we created Figure 1 to represent the extent to which the learner required more or less regulation by the teacher to correct the error. Prompts to the left of the continuum allowed the learner more agency and control of their own L2 utterances than those to the right. For example, a prompt that an error exists in an utterance provides the learner with less explicit other-regulation than a prompt that identifies exactly how to correct the error. Similarly, a prompt in which the teacher explains how to correct an error (e.g., "the subject is third person singular, so you need the $3^{\text {rd }}$ person singular form of the verb") provides the learner with slightly more agency and control in identifying and reformulating his/her error than providing the correct form (e.g., "it should be my brother disorganizes instead of my brother disorganize"). Thus, based on the tool shown in Figure 1, discursive moves that fulfilled the purposes to the left of the continuum (i.e. signaling the existence of an error) provided learners with more 
Language Teaching Research

DOI: $10.1177 / 1362168816654309$

agency and less explicit other-regulation than moves to the right of the continuum. To analyze the extent to which mediation was graduated, we examined the teacher's sequencing of prompts in each mediation sequence to determine the extent to which they progressed from moves that allowed for more learner agency in correcting their own errors and thus could lead to self-regulation, to those in which the teacher provided the correct form and thus learner's accurate L2 use remained other-regulated.

\section{+ Learner agency}

\begin{tabular}{|c|c|c|c|c|}
\hline $\begin{array}{c}\text { Existence of } \\
\text { Error }\end{array}$ & $\begin{array}{c}\text { Location of } \\
\text { Error }\end{array}$ & $\begin{array}{c}\text { Nature of } \\
\text { Error }\end{array}$ & $\begin{array}{c}\text { Explanation of } \\
\text { How to } \\
\text { Correct Error }\end{array}$ & $\begin{array}{c}\text { Recast }- \\
\text { Provision of } \\
\text { Correct Form }\end{array}$ \\
\hline
\end{tabular}

+ Teacher agency

Figure 1. Continuum of moves from less explicit other-regulation (left) to more explicit other-regulation (right)

After coding the lesson recordings, we consulted the written reflections and simulated recall session transcripts from each participant to determine their reported approach to DA. We identified their stated DA approach, any lists of scripted prompts included, and statements about tracking student progress. In cases in which teachers reported using scripted prompts (interventionist DA), we returned to the mediation sequences to code prompts based on the teachers' lists of scripted prompts.

\section{Findings}

To understand how the teachers' ability to use graduated prompting changed, we first analyzed their responses to student errors before the DA professional development series. Table 3 displays the number of recasts $(\mathrm{R})$ and prompts $(\mathrm{P})$ used by each teacher 
Language Teaching Research

DOI: $10.1177 / 1362168816654309$

during each mediation sequence in their pre-DA lesson. The number of mediation sequences in each teacher's lesson varied from three to eight.

[Insert Table 3 about here]

All teachers used similar proportions of recasts and prompts during the pre-DA lesson, with the exception of Diana. However, their use varied intriguingly. Recasts were the default teacher move after a student error in 12 of the 20 pre-DA mediation sequences. Prompts were used in eight of the 20 mediation sequences, but five of these eight ended with a teacher recast (denoted with an asterisk). There was one mediation sequence in which a peer recasted the correct form (Cielo's Mediation Sequence 8). Four potential mediation sequences that occurred in Sue's classroom are not displayed in the table because she ignored learners' errors, despite their direct relationship to her lesson objective.

We display Excerpt 1 to illustrate a mediation sequence that began with a prompt but terminated with a recast. This excerpt took place in Cielo's classroom during a lesson on expressing possibility using the grammatical pattern modal verb + have + past participle. The asterisk denotes the location of the error.

Excerpt 1. Cielo, Pre-DA

$1 \quad$ S1 He may have doing* goal

$2 \mathrm{~T}$ He may::: [prompt - existence of error]

3 S1 Ehhh have ehhh doing* goal.

$4 \quad \mathrm{~T} \quad$ He may have scored a goal. ((Writes the word scored on the board)) 
Ok? He may have scored a goal. [recast - provision of correct

\section{form]}

In turn 4, had Cielo instead chosen to provide a second prompt, one closer to the left of the continuum in Figure 1, she might have promoted the learner's understanding of how to express possibility in English and also collected important data about the learner's understanding of that grammatical pattern. Instead, her leap from a prompt that only suggested the existence of an error to a recast in which she reformulated the utterance represented a missed opportunity for creating a discursive space in which her mediation might have promoted learners' self-regulation.

Following the DA professional development workshops, all four teachers began to offer more prompts and fewer recasts. Table 4 shows the number of instances that each teacher used a recast or a prompt in each of the three DA lessons.

[Insert Table 4 about here]

Following the DA professional development series, recasts made up only $12 \%$ of the teachers' mediation moves whereas prompts made up $88 \%$ of the teachers' moves. Cielo and Sue both used recasts on seven occasions during their first DA lesson, but did not use any by their third DA lesson. Martin used recasts in every lesson, especially in his second DA lesson, but he also used more prompts than the other teachers. These data suggest that all teachers were attempting to mediate students' learning following the DA professional development series by using prompts that allowed learners more opportunities for self-regulation. Table 5 displays the number of mediation sequences 
Language Teaching Research

DOI: $10.1177 / 1362168816654309$

(MSs) that took place in each lesson for each teacher and the average number of teacher turns (TTs) that occurred in each mediation sequence.

[Insert Table 5 about here]

While the data displayed in Table 5 do not permit conclusions related to whether teachers' prompting was becoming more graduated and contingent based on learners' needs, they do illustrate an extension of the length of mediation sequences, due mainly to the teachers' use of more prompts than recasts as was shown in Table 4. Because the use of prompts leaves more room for learner agency in correcting their own errors, this created a discursive space in which learners might potentially have progressed from other-regulation to self-regulation. We examine each teacher's mediation qualitatively in the following section.

\section{Individual Cases - Graduated Prompting}

Following the DA professional development series, all of the teachers offered more prompts to create a discursive space in which learners had increasing opportunities for self-regulation. While Sue was unable to provide learners with graduated prompts, the other three teachers were able to appropriate this feature of DA. Appropriation refers to critically embracing the mediational means, "making it one's own" (Wertsch, 1998, p. 53 ) in the sense of using it to serve one's own mediational intentions. Of the four teachers, only Diana and Martin were able to provide learners with graduated and contingent mediation while also monitoring learner progress. We discuss each of these cases in turn. 
Language Teaching Research

DOI: $10.1177 / 1362168816654309$

a Sue - Prompts without graduation

Sue used a flexible approach to mediation for each of her three lessons. When a student made an error, she attempted to mediate using un-scripted prompts. In DA1, Sue's attempts at providing graduated prompts were unsuccessful, for she failed to offer any prompts and instead recast or ignored all errors (see Table 5). In a stimulated recall session, she stated, "I thought that I was doing a great job of using DA from the start, but as I watched myself I realized that I did not use it at all even though there were plenty of opportunities." After this realization, Sue began to prompt learners to reformulate their own errors in subsequent DA lessons. However, she relied on those prompts towards the right of the continuum in Figure 1, taking away learner agency in correcting their own errors. Excerpt 2, from a lesson in which students were describing their morning routines, provides an example from Sue's third DA lesson that is representative of her attempts at mediation across the DA lessons.

Excerpt 2. Sue, Mediation Sequence in DA 3

$1 \mathrm{~T} \quad$ Do you talk in the morning?

$2 \quad$ S1 $\quad$ Yeah

$3 \mathrm{~T} \quad$ Ok, so how would you say that?

4 S1 Me hablo.

(I talk to myself.)

5 T Close [prompt - existence of error], is that reflexive? [prompt - nature of error]

$6 \quad$ S1 Uh, no?

$7 \mathrm{~T} \quad$ Yes, why? 
Language Teaching Research

DOI: $10.1177 / 1362168816654309$

$8 \quad$ S1 Because I'm not doing it to myself.

While Sue's approach to mediation was improving in that she provided prompts rather than recasts, she continued to struggle to give learners' opportunities for reformulation. Sue provided two graduated prompts in turn 5, but did not pause between these prompts to allow the learner an opportunity for reformulation. It was unclear from the learner's response in Turn 6 whether he believed that the statement "Do you talk in the morning?" was not reflexive or that the statement "me hablo" was not reflexive. Rather than probing this ambiguity, Sue explicitly corrected the learner in turn 7 . Her response, too, was ambiguous, suggesting either that the student was correct that the English statement was not reflexive or that "me hablo" was reflexive and the student had provided an incorrect answer. The fact that Sue asked "why?" rather than "why not?" suggests the former. The interaction ended with the student's explanation of reflexivity in turn 8 which revealed his metalinguistic awareness of the concept. However, because the learner was not given an opportunity to reformulate his utterance, it was unclear whether he understood how to apply this concept. While Sue's prompts created a discursive space in which language development could potentially have occurred, it was unclear whether her prompts promoted the learner's movement along the continuum (Figure 1).

$b \quad$ Cielo - Progressing toward graduated prompting

Cielo also chose to use flexible prompting for all three DA lessons and was slightly more successful than Sue. Excerpt 3 shows a mediation sequence that occurred between Cielo (T) and a student (S1) during a lesson focused on gerunds in her second DA lesson.

Excerpt 3. Cielo, Mediation Sequence in DA 2 
Language Teaching Research

DOI: $10.1177 / 1362168816654309$

$1 \quad$ S1 $\quad$ get* married

2 T Get married. (.3) Can you::: remember what the activity is about?

[prompt - existence of error]

$3 \quad$ S1 (inaudible)

$4 \mathrm{~T}$ How. Remember, we are::: ((Points to a list of actions written on the board)) we have done copying, cheating, driving, exercising, cleaning, feeding and:::? ((Moves her hand to S1)) [prompt - nature of error]

$5 \quad$ S1 (No answer)

$6 \mathrm{~T}$ And:::? (.3) Remember, copyi:::ng, cheati:::ng, exercisi:::ng, cleani:::ng, feedi:::ng and:::? [prompt - nature of error]

$7 \quad$ S2 $\quad$ getting married

$8 \quad$ S3 Callate!

(shut up!)

$9 \quad$ S1 $\quad$ (Still no answer)

$10 \mathrm{~T}$ Is good! You have the right word, but not the right form. [prompt nature of error] That's the form [prompt - how to correct error] ((Points to board)) S2?

$11 \quad$ S2 $\quad$ Getting married

$12 \mathrm{~T}$ Did you listen to him? You? ((Points to another student))

$13 \quad$ S3 (inaudible)

$14 \mathrm{~T}$ Ammm, copying, cheating, driving [prompt - nature of error]

$15 \quad$ S1 $\quad$ Getting 
Language Teaching Research

DOI: $10.1177 / 1362168816654309$

As Excerpt 3 illustrates, Cielo's first prompt in turn 2 was a metalinguistic question intended to signal to $\mathrm{S} 1$ that there was an error in his utterance. On the continuum displayed in Figure 1, this prompt allowed the learner the most opportunity for selfregulation, indicating that an error existed without giving any information about the type of error or its location. Because S1 was unable to repair the error with this prompt, Cielo exemplified other gerunds in turn 4, indicating the nature of the error. In turn 6, Cielo repeated this prompt and also gestured toward the board on which other gerunds were written. This gesture and accompanying statement, "That's the form" were intended to show the learner how to correct the error, a move further along the continuum toward other-regulation. In turn 14, Cielo again exemplified other gerunds to indicate the nature of the error to the learner, moving back along the continuum and again providing S1 increasing responsibility for self-regulation. In turn $15, \mathrm{~S} 1$ was able to reformulate her response, but only after a peer provided the correct reformulation. While Excerpt 3 suggests that Cielo was making some progress in her ability to deliver graduated prompts, her inability to mediate the learner's reformulation suggests that Cielo herself required additional mediation.

c Diana and Martin-Towards appropriation

Diana and Martin were both able to provide learners with somewhat graduated and contingent mediation while also tracking the prompting that students' required. However, their paths for doing so varied slightly. Like Cielo and Sue, Martin initially chose to use flexible prompts and struggled to mediate learning. Excerpt 4 is a mediation sequence from DA 1 which focused on giving recommendations for the treatment of 
Language Teaching Research

DOI: $10.1177 / 1362168816654309$

medical ailments. To begin a role-play, a student (S1) attempted to state that she had the

flu. Excerpt 4 shows Martin's attempt to mediate.

Excerpt 4. Martin, Mediation Sequence during DA 1

$1 \quad$ S1 I am* very the flu

$2 \mathrm{~T} \quad \mathrm{I}$ am... [prompt - location of error]

$3 \quad$ S1 Very* the flu

$4 \quad \mathrm{~T} \quad$ The flu? [prompt - existence of error]

$5 \quad$ S1 The flu

6 T The flu like (coughing) you know... ok Carla, I am* very the flu?... I am* very the flu? [prompt - existence of error]

$7 \quad$ S2 $\quad$ Tiene fiebre (she has a fever)

$8 \quad \mathrm{~T} \quad$ Yes, but I am*? [prompt - location of error]

$9 \quad$ Ss $\quad \mathrm{Xxx}$

$10 \mathrm{~T} \quad$ Yes, but I am*? [prompt - location of error]

11 Ss (inaudible)

$12 \mathrm{~T}$ or ... I mean is correct to say I am* the flu?

[prompt - existence of error]

13 S3 I have

14 S1 No

$15 \mathrm{~T} \quad$ Yes

16 S3 I have very* the flu 
Language Teaching Research

DOI: $10.1177 / 1362168816654309$

In Excerpt 4, Martin vacillated between providing the learner with prompts indicating that there was an error in the utterance and prompts that indicated the location of the error. Although these prompts were insufficient for S1 to correct her error, Martin failed to deliver prompts farther along the continuum toward other-regulation that indicated the nature of the error or how to correct it. In turn 13, a classmate (S3) interrupted the mediation sequence to assist and Martin confirmed the contribution. The interaction continued as Martin next attempted to prompt the learner to remove the word very in the utterance. Similar to Sue's attempts to mediate, Martin's prompts were not graduated and, in many cases, were quite confusing. Additionally, neither of the errors in this utterance related to the lesson objective.

However, after DA 1, Martin switched to a scripted approach, explaining that "The lack of planning, not being as highly skillful in the issue of DA did not allow me to better mediate between the student and the instruction process." As a result, Martin created a list of prompts that were each assigned a point value (see Table 6).

[Insert Table 6 about here]

Using these prompts, Martin's prompting became graduated, more contingent upon learners' needs, and more focused on his lesson objective in subsequent lessons. Excerpt 5 occurred in a lesson focused on third person present-tense verb conjugations during Martin's third DA lesson recording. The codes indicate Martin's scripted prompts from Table 5, accompanied by our coding of where each prompt corresponds to our continuum. 
Excerpt 5. Martin, Mediation Sequence during DA 3

1 S1 When I do arrange my room but my brother disorder* [Prompt 1] ${ }^{2}$

$2 \mathrm{~T} \quad$ Disorganize you mean?

$3 \quad$ S1 (Student does not answer)

$4 \quad \mathrm{~T} \quad$ Any mistake? Any mistake? [Prompt 2 - existence of error]

$5 \quad$ S1 (no response)

6 T No? Listen to this sentence; can you please repeat the sentence aloud?

[Prompt 2 - existence of error]

7 S1 I do arrange my room but my brother disorganize*

$8 \mathrm{~T} \quad$ Disorganize... you mean I organize my room but my brother disorganize* it [Prompt 3 - location of error] My question is, what's the mistake?

$9 \quad$ S1 Repeat

$10 \mathrm{~T}$ The sentence is: I organize my room or my bedroom but my brother disorganize* it [Prompt 4 - location of error]...Any mistake?

$11 \quad$ S1 Disorganizes

$12 \mathrm{~T}$ Very good, third person, because my brother is a...

13 Ss $\mathrm{He}$

$14 \mathrm{~T}$ Is a he, very good

15 S1 Third person

Excerpt 5 is representative of Martin's progress at mediating learners. After clarifying what the student was trying to say in turn 2, Martin began to deliver the prompts that he 
Language Teaching Research

DOI: $10.1177 / 1362168816654309$

had scripted in advance. Martin's prompts did not correspond exactly to our own

continuum in that Martin had multiple prompts that signaled the existence of an error or the location of an error. However, more importantly, Martin's prompting provided the learner with the information required to repair his own utterance while also giving him the discursive space to do so. After delivering his fourth prompt in turn 10, in which he emphasized the incorrect verb, S1 was able to use the mediation provided by Martin to reformulate his own utterance.

Although Martin scripted his prompts in advance, he did not always strictly adhere to them, as illustrated in turns 4 and 6 when he delivered his second prompt twice. Following DA 3, Martin reflected,

I do not know if it is prudent, but I think we can plan the prompts but also be flexible when we apply them, then in this case we would not only be using interventionist, but we would also apply both strategies at the same time because as it happened to me this last class, the prompts were modified slightly depending on the situation and what happened with the student. Martin described how, even in cases in which he was unable to follow these prompts exactly, he was able to slightly modify them to be more responsive to the learner. The process of thinking through each prompt, and their presence as a tool during the lesson, may have served to mediate Martin's appropriation of providing learners with graduated and contingent mediation.

Diana, too, attempted to deliver scripted prompts to mediate students' awareness and reformulation of their errors. During each DA lesson, she carried a list of scripted prompts tailored to her lesson objective along with a grid to record students' progress. 
Language Teaching Research

DOI: $10.1177 / 1362168816654309$

Unlike the other three participants, Diana decided to use an interventionist DA approach during her first DA lesson before transitioning to a "semi-interventionist" approach in which she scripted prompts but only loosely adhered to them. During her first lesson, Diana attempted to strictly follow her prompts, which were as follows:

1. "Look at the verb in the sentence again."

2. "What past tense should the verb be in? How do you know?"

3. "What subject is the verb referring to?"

4. "Look at the verb again. Is that the preterite/imperfect ending for the verb for (yo/tú/él/ella, etc.)?"

5. "Does the verb have a stem change or suffix change in the preterite/imperfect? If so, how does it change?"

6. "What is the preterite/imperfect verb ending for (yo/ tú/ él/ella, etc.)?"

7. And finally I would give and explain the correct answer.

Excerpt 6 took place during Diana's first DA implementation in a lesson that focused on past tense narration. As Excerpt 6 highlights, Diana was the only one of the four teachers who was somewhat successful with providing graduated and contingent prompting during her first attempt at DA implementation. Each prompt is numbered based on Diana's scripted list and is accompanied by our coding scheme.

Excerpt 6. Diana, Mediation Sequence during DA 1

1 T Okay, nosotros fueron* al cine. Ok look at the verb. Read it again. (prompt 1 - location of error)

(okay, we went* to the theatre.)

2 S1 Is it fuiamos*? 
Language Teaching Research

DOI: $10.1177 / 1362168816654309$

$3 \mathrm{~T}$ So then, what's the subject referring to? (prompt 3 - nature of error)

4 S1 fuimos (says it right, repeats after another student) (we went)

$5 \mathrm{~T} \quad$ Yeah, and what is the verb referring to? (prompt 3 - nature of error)

6 S1 Like they go...

$7 \quad \mathrm{~T} \quad$ So the subject is? (prompt 3 - nature of error)

8 S1 Oh, they or ...

9 T Well, let's see. Subject (points to board with conjugations). (prompt 3 how to correct error)

10 S1 Nos...

11 T Yes, nosotros. Si, muy bien. So...

(Yes, we. Yes, very good. So...)

12 S1 fuimos

(we went)

$13 \mathrm{~T} \quad$ Muy bien.

Like Martin, Diana was not able to deliver her prompts verbatim and deviated from her continuum slightly. For example, in Excerpt 6, Diana appropriately skipped her second prompt because the learner had already correctly chosen to use the preterit rather than the imperfect aspect. In turn 4, after delivering her third prompt, the learner correctly reformulated her utterance. However, Diana continued with her prompting to ensure that the learner understood the concept. In turns 5, 7, and 9, Diana prompted the learner to state the subject of her sentence. The learner struggled to identify the subject until turn 10 when Diana pointed to the board to show the learner the subjects and accompanying suffixes. In turn 11, Diana prompted the learner to identify the appropriate suffix for the identified subject and the learner responded with the correct form of the verb. 
Like Martin, it is possible that the process of planning the scripted prompts, and their presence during the lessons, served to mediate Diana's own ability to mediate. Diana stated,

I wanted the interaction to be less scripted, though the prompts are scripted, so the conversation could be more natural. I did not want to distract the students by looking at my list of prompts so I did my best to follow the same order of prompts for each student, which was a bit tricky because not each student had the same problem.

In subsequent lessons, Diana continued to use her newly termed "semi-interventionist" approach.

\section{Individual Cases - Tracking learner progress}

As described previously, a second defining characteristic of DA is that the teacher tracks learners' responses to prompting to gauge what forms of mediation might be required in subsequent instruction. Neither Cielo nor Sue were able to track learners' responses to prompting during DA implementation. When asked whether she tracked learners' progress, Cielo stated, "Es difícil hacer la diferenciación, no la hice...puedo hablarte en términos general y te podría decir que la mayoría, que la mayoría respondió positivamente a la actividad" (It is difficult to distinguish, I did not, but I can tell you in general terms that the majority, the majority responded positively to the activity). Sue, too, indicated that she was unable to track learners' responses to her prompts. Following DA 3, Sue reflected, "I am still struggling to formally keep track of students' errors. I make mental notes in my head of who is really struggling and I will talk to my cooperating teacher about it after class, but I never formally take notes on my mediation 
Language Teaching Research

DOI: $10.1177 / 1362168816654309$

with the students." Thus, our findings suggest that although Sue and Cielo were appropriating the DA characteristic of using prompts rather than recasts, they did not appropriate the characteristic of tracking students' responses.

Unlike Cielo and Sue, both Martin and Diana were able to track a selection of learners during the DA lessons. Diana was able to record the number of prompts required by four learners throughout all three of her DA lessons. In her DA proposal, she described that she would track "a struggling student, an average student, an above average student and a student with an Individualized Education Plan (IEP)" to "see how students with different academic abilities in Spanish compare when given DA mediation." On her grid, she recorded the name of the student, the error, the correct form, and how many prompts the student needed to correctly reformulate the error. In some cases, she made a note to herself indicating a clue from the text that led the student to reformulate his error.

Martin was able to track the number of prompts required by learners' during his third DA lesson. Not unlike Diana, Martin created a grid to track three learners. However, Martin went one step further and also included a section in which he tallied the number of prompts required in each mediation sequence. Martin reflected on his third DA lesson in writing following implementation,

Five more [mediation sequences] were tracked during the speaking activity, in \#1, the student needed 8 out of eight prompts to finally get the correct answer which was explained and given by the teacher, in the participation \# 2, the teacher only mediated 2 times, in \# 3 also 2 , however in \# 4, six were needed but in \# 5 the answer was correct so no mediation 
was needed. From this sequence of participations, it is clear that in all cases except \#4, all students had good performance because of the mediation provided in previous cases.

This narrative suggests that Martin's tally served to gauge the overall progress of the group of learners, aiding his ability to make decisions about the extent to which they had grasped the linguistic features being studied. Furthermore, he stated that, "Tracking learners' participation on the checklist served as input when issuing the final grades for the grading period". Both Diana and Martin were able to appropriate the process of tracking learners' required mediation and adopt it for their own contexts. Because we did not record adjacent lessons, we were unable to analyze the extent to which each teacher used their records to plan subsequent instruction.

\section{Conclusions}

All four teachers' ability to mediate changed following the DA professional development series as they endeavored to implement DA in their classrooms. Pre-DA lessons revealed that all teachers struggled to provide graduated prompting, often using recasts rather than prompts in short mediation sequences. Following professional development, each teacher began to use more prompts and fewer recasts, potentially providing learners with more agency to progress toward self-regulation. However, the teachers appropriated two defining characteristics of DA to varying degrees, suggesting that some may have required additional mediation. Only two of the four teachers were able to graduate prompts and track learners' responsiveness to mediation during ongoing interaction. It is well-documented that teachers' appropriation of new concepts and their 
Language Teaching Research

DOI: $10.1177 / 1362168816654309$

implementation in practice is a complex and revolutionary process that takes substantial time and practice and is subject to a variety of tensions and contradictions (Smagorinsky, Cook, \& Johnson, 2003). Such a process requires continuous mediation and support (van Compernolle \& Henery, 2015).

Just as teachers must carefully plan every aspect of their lessons as they are learning to teach, they, too, must carefully plan their discursive responses to student errors as they learn to mediate. Although we attempted to mediate teachers' understanding of DA during the professional development series and stimulated recall sessions, we allowed each teacher to develop their own DA approach. We recognize the value of interactionist approaches to DA and the affordances of flexible mediation that give teachers more freedom to move back and forth along the continuum, re-opening the discursive space for self-regulation when necessary (Lantolf \& Poehner, 2013, 2014; Poehner, 2008; Rahimi, Kushki, \& Nassaji, 2015). However, findings from the present study suggested that using scripted prompts for mediation may be more within the ZPD of teachers initially learning to implement DA. Our findings confirmed those of others that all teachers struggled to make split-second decisions about how to respond appropriately to learners' oral discourse (Author \& Colleague, xxxx; Walsh, 2006). The cases of Diana and Martin suggested that the process of thinking through lesson objectives, anticipating learners' misconceptions, and planning mediation may have supported their development. The lists of prompts, carried by the teachers while teaching, may have served as a crutch, reducing the cognitive load of instantly understanding a student's error and determining appropriate mediation. Additionally, these prompts may have helped the teacher to focus only on those errors that directly related to the lesson 
Language Teaching Research

DOI: $10.1177 / 1362168816654309$

objective. As suggested in existing research (Author, xxxx), scripted prompts were too restrictive in that they were not always appropriate for the unfolding discourse and did not allow bidirectional movement on the continuum in Figure 1, supporting Aljaafreh and Lantolf"s (1994) contention that, "adjustments cannot be determined a priori; rather, they must be collaboratively negotiated on-line with the learner" (p. 466). However, both Diana and Martin were able to vary from their scripted prompts when necessary. Thus, scripting prompts before the lesson may have eased the transition in cases in which it was necessary to deviate from those prompts to deliver more flexible mediation. In future DA professional development, teachers new to DA, even those with many years of teaching experience, might first engage in the process of anticipating students' misconceptions and creating a list of graduated prompts tailored to their lesson objective for mediation.

As we continue our work in this area, we plan to broaden the horizons to consider other factors that likely influenced teachers' DA implementation. Subsequent investigations must consider teachers' beliefs and attitudes and the complex ways in which they influence classroom practice (Borg, 2006; Johnson, 2009; Lantolf \& Johnson, 2007). While the present study focused almost solely on practice-based data (see Cross, 2010), an integrated analysis of thought-based data sources would provide a fuller picture of teachers' ontogenetic development (Negueruela-Azarola, 2011; van Compernolle \& Henery, 2015; Williams et al., 2013). Additionally, classroom contexts deserve a detailed focus in research of this kind. The present study included a wide variety of variables, including nationality, experience, language, and methods of lesson video-recording. Each of these variables, in addition to others such as the number of students in the classroom or issues of classroom management surely played a significant role in each teacher's 
Language Teaching Research

DOI: $10.1177 / 1362168816654309$

approach and appropriation of DA. Finally, this investigation focused narrowly on teachers' approach to mediation as triggered by a learner error during classroom instruction. To be sure, classroom mediation often occurs without the presence of learner errors. By examining mediation more broadly and expanding data collection to include teachers' personal beliefs and contextual affordances and constraints, future research has the potential to provide important insights into how we might best support teachers' appropriation of the concept of DA.

Notes

${ }^{1}$ By using the term 'recast' from the corrective feedback literature we do not intend to imply that DA and corrective feedback correspond to the same process. Rather, we see no need for adopting another label for a discursive move such as recasts that is well established in the literature.

${ }^{2}$ This does not meet the definition of a prompt, but was labeled a prompt by Martin in his list of scripted prompts.

\section{References}

Ableeva, R. (2008). The effects of dynamic assessment on L2 listening comprehension. In J. P. Lantolf \& M. E. Poehner (Eds.), Sociocultural theory and the teaching of second languages (pp. 57-86). London, UK: Equinox.

Aljaafreh, A., \& Lantolf, J. P. (1994). Negative feedback as regulation and second language learning in the zone of proximal development. Modern Language Journal, $78,465-483$. 
Language Teaching Research

DOI: $10.1177 / 1362168816654309$

Antón, M. (2009). Dynamic assessment of advanced second language learners. Foreign Language Annals, 42(3), 576-598.

Borg, S. (2006). Teacher cognition in language education: Research and practice. London: Continuum.

Chaiklin, S. (2003). The zone of proximal development in Vygotsky's analysis of learning and instruction. In A. Kozulin, B. Gindis, V. S. Ageyev, \& S. M. Miller (Eds.), Vygotsky's educational theory in cultural context (pp. 39-63). Cambridge, UK: Cambridge University Press.

Cross, R. (2010). Language teaching as sociocultural activity: Rethinking language teacher practice. The Modern Language Journal, 94(3), 434-452.

Davin, K.J. (2013). Integration of dynamic assessment and instructional conversations to promote development and improve assessment in the language classroom. Language Teaching Research, 17, 303-322.

Davin, K.J., Troyan, F.J., \& Hellmann, A. (2014). Classroom dynamic assessment of reading comprehension with second language learners. Language and Sociocultural Theory, 1, 1-23.

Desoete, A., Roeyers, H., Buysse, A., \& De Clerq, A. (2002). Dynamic assessment of metacognitive skills in young children with mathematics-learning disabilities. In G. M. van der Aalsvoort, W. C. M. Resing, \& A. J. J. M. Ruijssenaars (Eds.), Learning potential assessment and cognitive training: Actual research and perspectives in theory building and methodology (pp. 307-333). Amsterdam: Elsevier Science Ltd.

Golombek, P. R. (2011). Dynamic assessment in teacher education: Using dialogic video 
Language Teaching Research

DOI: $10.1177 / 1362168816654309$

protocols to intervene in teacher thinking and activity. In K. E. Johnson \& P. R.

Golombek (Eds.). Research on second language teacher education: A sociocultural perspective on professional development (pp. 121-135). New York: Routledge.

Johnson, K. E. (2009). Second language teacher education: A sociocultural perspective. New York, NY: Routledge.

Lantolf, J. P. (2012). Sociocultural theory: A dialectical approach to L2 research. In S. M. Gass \& A. Mackey (Eds.), The Routledge handbook of second language acquisition (pp. 57-72). New York: Routledge.

Lantolf, J. P., \& Johnson, K. E. (2007). Extending Firth and Wagner's (1997) ontological perspective to L2 classroom praxis and teacher education. The Modern Language Journal, 91(Focus Issue), 877-892.

Lantolf, J. P., \& Poehner, M. E. (2011a). Dynamic assessment in the classroom: Vygotskian praxis for second language development. Language Teaching Research, $15(1), 11-33$.

Lantolf, J. P., \& Poehner, M. E. (2011b). Dynamic assessment in the foreign language classroom: A teacher's guide (2nd ed.). University Park, PA: CALPER.

Lantolf, J. P., \& Poehner, M. E. (2013). The unfairness of equal treatment: Objectivity in L2 testing and dynamic assessment. Educational Research and Evaluation, 19(2-3), $141-157$.

Lantolf, J. P., \& Poehner, M. E. (2014). Sociocultural theory and the pedagogical imperative in L2 education. New York, NY: Routledge.

Lidz, C. S. (2014). Leaning toward a consensus about Dynamic Assessment: Can we? Do we want to? Journal of Cognitive Education and Psychology, 13(3), 292-307. 
Language Teaching Research

DOI: $10.1177 / 1362168816654309$

Lyster, R., \& Ranta, L. (1997). Corrective feedback and learner uptake: Negotiation of form in communicative classrooms. Studies in Second Language Acquisition, 19(1), $37-66$.

Nassaji, H. (2009). Effects of recasts and elicitations in dyadic interaction and the role of feedback explicitness. Language Learning, 59(June), 411-452.

Negueruela-Azarola, E. (2011). Beliefs as conceptualizing activity: A dialectical approach for the second language classroom. System, 39(3), 359-369.

Poehner, M. E. (2008). Dynamic assessment: A Vygotskian approach to understanding and promoting L2 development. Berlin: Springer.

Poehner, M. E., \& Lantolf, J. P. (2013). Bringing the ZPD into the equation: Capturing L2 development during computerized dynamic assessment (C-DA). Language Teaching Research, 17(3), 323-342.

Poehner, M. E., \& van Compernolle, R. A. (2013). L2 development around tests: Learner response processes and dynamic assessment. International Review of Applied Linguistics, 51(4), 353-377.

Poehner, M. E., Zhang, J., \& Lu, X. (2015). Computerized dynamic assessment (C-DA): Diagnosing L2 development according to learner responsiveness to mediation. Language Testing, 32(3), 337-357.

Rahimi, M., Kushki, A., \& Nassaji, H. (2015). Diagnostic and developmental potentials of dynamic assessment for L2 writing. Language and Sociocultural Theory, 2(2), $185-208$.

Rassaei, E. (2014). Scaffolded feedback, recasts, and L2 development: A sociocultural 
Language Teaching Research

DOI: $10.1177 / 1362168816654309$

perspective. Modern Language Journal, 98(1), 417-431.

Smagorinsky, P., Cook, L. S., \& Johnson, T. S. (2003). The twisting path of concept development in learning to teach. Teachers College Record, 105(8), 1399-1436.

Song, S., \& Kellogg, D. (2011). Word meaning as a palimpsest: A defense of sociocultural theory. Modern Language Journal, 95(4), 589-604.

van Compernolle, R. A. (2013). Interactional competence and the dynamic assessment of L2 pragmatic abilities. In S. Ross \& G. Kasper (Eds.), Assessing second language pragmatics (pp. 327-353). Basingstoke, UK: Palgrave Macmillan.

van Compernolle, R. A., \& Henery, A. (2015). Learning to do concept-based pragmatics instruction: Teacher development and L2 pedagogical content knowledge. Language Teaching Research, 19(3), 351-372.

Vygotsky, L. S. (1978). Mind in society: The development of higher mental processes. Cambridge, MA: Harvard University Press.

Vygotsky, L. S. (1987). The collected works of L. S. Vygotsky, Volume 1. Problems of general psychology including the volume Thinking and speech. In R.W. Rieber and A. S. Carton (Eds.) New York: Plenum Press.

Walsh, S. (2006). Investigating classroom discourse. New York, NY: Routledge.

Wertsch, J. V. (1998). Mind as action. Oxford, UK: Oxford University Press.

Wertsch, J. V. (2007). Mediation. In H. Daniels, M. Cole, \& J. V. Wertsch (Eds.), The Cambridge companion to Vygotsky (pp. 178-192). New York, NY: Cambridge University Press.

Williams, L., Abraham, L. B., \& Negueruela-Azarola, E. (2013). Using concept-based 
Language Teaching Research

DOI: $10.1177 / 1362168816654309$

instruction in the L2 classroom: Perspectives from current and future language teachers. Language Teaching Research, 17(3), 363-381. 
Language Teaching Research

DOI: $10.1177 / 1362168816654309$

Table 1. Pseudonyms, years of teaching experience, L2, and level.

\begin{tabular}{llll} 
Pseudonym & Years of Experience & Language Taught & Level Taught \\
\hline Cielo & 10 & English & $11^{\text {th }}$ grade \\
Martin & 10 & English & $9^{\text {th }}$ grade \\
Diana & 0 & Spanish & High School (H.S.) \\
& & & Level III \\
Sue & 0 & Spanish & H.S. Level II
\end{tabular}


Language Teaching Research

DOI: $10.1177 / 1362168816654309$

Table 2. Teachers' Approach to DA in each DA lesson

$\begin{array}{llll}\text { Pseudonym } & \text { DA 1 } & \text { DA 2 } & \text { DA 3 } \\ \text { Cielo } & \text { Interactionist } & \text { Interactionist } & \text { Interactionist } \\ \text { Martin } & \text { Interactionist } & \text { Interventionist } & \text { Interventionist } \\ \text { Diana } & \text { Interventionist } & \text { Semi-interventionist } & \text { Semi-interventionist } \\ \text { Sue } & \text { Interactionist } & \text { Interactionist } & \text { Interactionist }\end{array}$


Language Teaching Research

DOI: $10.1177 / 1362168816654309$

Table 3. Teachers' Use of Recasts and Prompts in Pre-DA Lessons

Pseudonym

$\begin{array}{lllllllll}\text { Cielo } & & \text { Martin } & & \text { Diana } & & \text { Sue } \\ \text { R } & \text { P } & \text { R } & \text { P } & \text { R } & \text { P } & \text { R } & \text { P }\end{array}$

Mediation Sequence 1

10

10

$\begin{array}{llll}1 & 0 & 1 & 0\end{array}$

Mediation Sequence 2

10

$0 \quad 1$

$\begin{array}{llll}1 & 0 & 1 & 0\end{array}$

Mediation Sequence 3

10

10

$\begin{array}{llll}1 & 0 & 0 & 2\end{array}$

Mediation Sequence 4

$1 * \quad 1$

10

Mediation Sequence 5

Mediation Sequence 6

10

1* 2

Mediation Sequence 7

$1 * \quad 2$

$1^{*} \quad 2$

Mediation Sequence 8

peer 3

Total

$\begin{array}{ll}7 & 8\end{array}$

55

$\begin{array}{llll}3 & 0 & 2 & 2\end{array}$ 
Language Teaching Research

DOI: $10.1177 / 1362168816654309$

Table 4. Number of recasts and prompts used by each teacher across three DA lessons.

MS: Mediation sequence

\begin{tabular}{lccc|ccc|cc|llll} 
& \multicolumn{2}{l}{ Cielo } & & Martin & & Diana & & \multicolumn{2}{|l}{ Sue } & \\
DA Lesson & $\mathbf{1}$ & $\mathbf{2}$ & $\mathbf{3}$ & $\mathbf{1}$ & $\mathbf{2}$ & $\mathbf{3}$ & $\mathbf{1}$ & $\mathbf{2}$ & $\mathbf{3}$ & $\mathbf{1}$ & $\mathbf{2}$ & $\mathbf{3}$ \\
MSs & 5 & 5 & 1 & 9 & 7 & 8 & 4 & 5 & 6 & 10 & 9 & 5 \\
\hline Recasts & 7 & 2 & 0 & 4 & 19 & 5 & 0 & 3 & 1 & 7 & 0 & 0 \\
Prompts & 40 & 25 & 9 & 55 & 51 & 75 & 24 & 17 & 16 & 0 & 24 & 14
\end{tabular}


Language Teaching Research

DOI: $10.1177 / 1362168816654309$

Table 5. Average Number of Teacher Turns in Response to Error

\begin{tabular}{lcccccccc} 
& \multicolumn{2}{c}{ Pre-DA } & \multicolumn{2}{c}{ DA 1 } & \multicolumn{2}{c}{ DA 2 } & \multicolumn{2}{c}{ DA 3 } \\
& MSs & TTs & MSs & TTs & MSs & TTs & MSs & TTs \\
Cielo & 8 & 1.9 & 5 & 9.6 & 5 & 5.4 & 1 & 9 \\
Martin & 6 & 1.7 & 9 & 5.2 & 7 & 10.1 & 8 & 9.6 \\
Diana & 3 & 1.0 & 4 & 6.0 & 5 & 3.4 & 6 & 2.8 \\
Sue & 3 & 1.3 & 10 & 0.7 & 9 & 2.8 & 5 & 2.8
\end{tabular}


Language Teaching Research

DOI: $10.1177 / 1362168816654309$

Table 6. Martin's scripted prompts for interventionist DA

PROMPT

$1 \quad$ Teacher lets the student try without assistance

2 Teacher asks student to check the whole statement and look for mistake(s)

3 Teacher repeats the part of the statement where the mistake(s) is (are)

4 The teacher puts emphasis on the mistake (word(s)) questioning

5 Teacher ask a question that might provide the clue for the student to realize the reason of the mistake; form of verbs $3^{\text {rd }}$ person, auxiliary in negative and questions

6 The teacher will directly point out the mistake(s) 2

$7 \quad$ The teacher will give explicit explanation 1

8 The teacher will provide the answer 0
5

4 